\title{
ANALISIS PERPINDAHAN PANAS KONVEKSI PADA PENERIMA VOLUMETRIK DI MENARA SURYA MENGGUNAKAN METODE VOLUME HINGGA
}

\section{Analysis of Convection Heat Transfer on Volumetric Receiver in Solar Tower Using Finite Volume Method}

\author{
Arif Fatahillah $^{1 *}$, Dafik ${ }^{2}$, Putri Nur Amalina ${ }^{3}$ \\ ${ }^{1,2,3}$ Pendidikan Matematika, FKIP, Universitas Jember \\ Jln. Kalimantan 37 Kampus Bumi Tegalboto, Jember, 68121, Indonesia \\ e-mail:1*arif.fkip@unej.ac.id ; ${ }^{2}$ d.dafik@gmail.com ; 3 putri29amalina@gmail.com
}

Corresponding author*

\begin{abstract}
Abstrak
Dalam kehidupan nyata, energi listrik telah menjadi sumber daya penting yang dibutuhkan oleh manusia. Bahan bakar yang berbasis fosil seperti minyak bumi membutuhkan waktu yang sangat lama dalam pembentukannya, sehingga mengakibatkan beberapa peneliti mencoba untuk menciptakan sumber energi baru dengan cara mengeksploitasi energi matahari, salah satunya adalah menara surya. Menara surya adalah salah satu alat yang telah didirikan oleh para peneliti, yang memiliki alat penerima volumetrik yang berfungsi sebagai penukar panas. Penelitian ini berfokus pada aliran udara pada penerima volumetrik dengan memodelkan masalah tersebut untuk selanjutnya diselesaikan dengan menggunakan metode volume hingga. Desain dibangun berdasarkan kecepatan angin dan suhu di sekitar menara surya untuk mengetahui efek kecepatan angin dan suhu di sekitar terhadap suhu di dalam penerima volumetrik. Berdasarkan hasil simulasi menggunakan perangkat lunak MATLAB, ditemukan bahwa kecepatan angin $2 \mathrm{~m} / \mathrm{s} ; 2,5 \mathrm{~m} / \mathrm{s}$ dan $3 \mathrm{~m} / \mathrm{s}$ memiliki nilai rata-rata suhu penerima volumetrik sebesar $235,6945^{\circ} \mathrm{C}, 123,3843^{\circ} \mathrm{C}$, dan $23,57384{ }^{\circ} \mathrm{C}$ dengan kesalahan relatif 0,009676 . Di sisi lain dengan kecepatan angin yang sama, efek suhu sekitar menara surya adalah $12,66606^{\circ} \mathrm{C}$ $69,70398{ }^{\circ} \mathrm{C}$, dan $176,5612^{\circ} \mathrm{C}$ dengan kesalahan relatif 0,001366 .
\end{abstract}

Kata Kunci : Menara Surya, Penerima Volumetrik, Metode Volume Hingga

\begin{abstract}
In the real life, electric energy has become an essential resource which is needed by men. The commonly used fossil-based fuel which needs very long time in forming can cause some researchers try to create new energy resource which exploits solar energy. Solar tower is one of the tools which has been established by researchers. Thus, there is volumetric receiver inside the solar tower which has function as heat exchanger. Mathematic model which is employed in this research focuses on the air flow on volumetric receiver by applying finite volume method. The design is built based on wind speed and temperature around the solar tower in order to know the effect of wind speed and the temperature around toward the temperature inside the volumetric receiver. Based on the simulation result using MATLAB software, it is found that of wind speed $2 \mathrm{~m} / \mathrm{s} ; 2.5 \mathrm{~m} / \mathrm{s}$ and $3 \mathrm{~m} / \mathrm{s}$ has an average temperature value on the volumetric receiver $235.6945{ }^{\circ} \mathrm{C}, 123.3843{ }^{\circ} \mathrm{C}$, and $23.57384{ }^{\circ} \mathrm{C}$ with relative error 0,009676 . On the other hand, the effects of temperature around are about $12.66606^{\circ} \mathrm{C}$, $69.70398^{\circ} \mathrm{C}$, and $176.5612^{\circ} \mathrm{C}$ with relative error 0.001366.
\end{abstract}

Keywords: Solar tower, Volumetric receiver, finite volume method. 


\section{PENDAHULUAN}

Dalam kehidupan sehari-hari, energi listrik sudah menjadi kebutuhan pokok yang sangat dibutuhkan oleh manusia. Energi listrik dapat digunakan sebagai sumber energi, sarana hiburan, penghasil panas, penghasil gerak serta sebagai penerangan [1]. Umumnya, bahan bakar yang digunakan dalam pembentukkan energi tersebut yaitu bahan bakar fosil. Namun saat ini bahan bakar fosil semakin berkurang dan proses pembentukkan bahan bakar fosil tersebut membutuhkan waktu bertahun-tahun. Hal ini menyebabkan para peneliti menciptakan energi terbarukan dengan memanfaatkan cahaya matahari. Menara surya merupakan salah satu alat yang diciptakan oleh para peneliti dapat dilihat pada Gambar 1. Di dalam menara surya terdapat penerima volumetrik yang berfungsi sebagai penukar panas dapat dilihat pada Gambar 2[2].

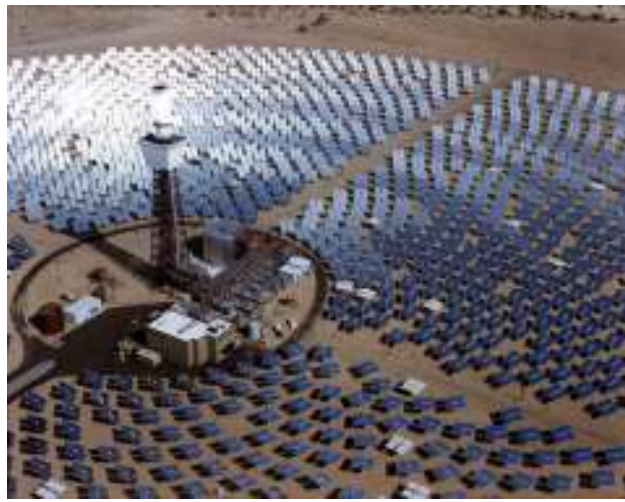

Gambar 1. Menara Surya ( Sumber : phys.org )
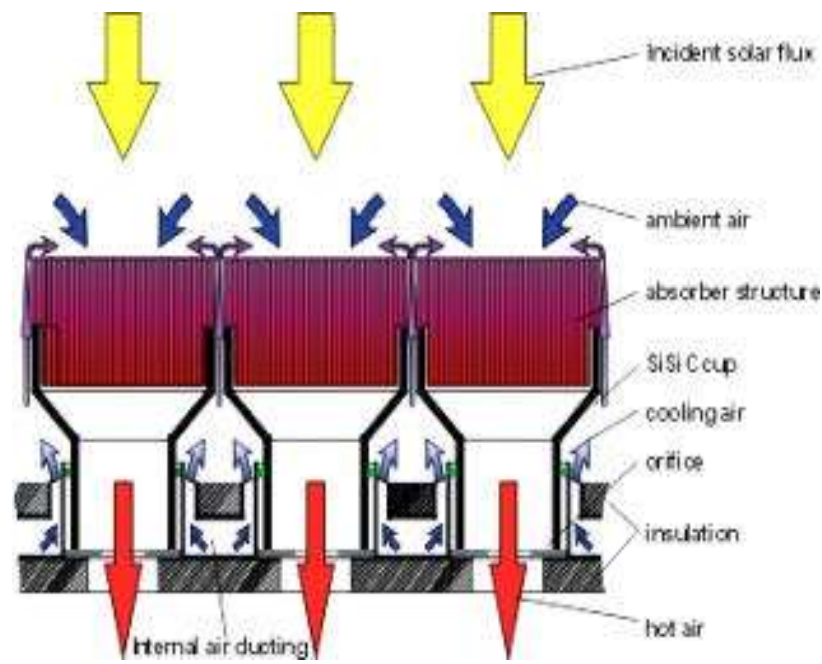

Gambar 2. Penerima Volumetrik ( Sumber : www.dlr.de )

Dalam penelitian ini dibentuk model persamaan diferensial matematika mengenai penukaran panas yang terjadi di menara surya. Model yang terbentuk akan disimulasikan dan dianalisis menggunakan software MATLAB dan FLUENT. Obyek penelitian ini difokuskan pada pengaruh kecepatan angin serta temperatur di sekitar menara surya terhadap panas yang dihasilkan di penerima volumetrik.

Pada penelitian ini akan menganalisa dan menyelesaikan model dari analisis aliran udara yang terjadi di penerima volumetrik secara numerik menggunakan metode Volume Hingga. Tujuan utama penelitian ini adalah untuk mengetahui proses perpindahan panas dalam penerima volumetrik di menara surya berdasarkan kecepatan angin dan untuk mengetahui proses perpindahan panas dalam penerima volumetrik di menara surya berdasarkan temperatur sekitar menara surya.

Persamaan diferensial yang digunakan untuk penerima volumetrik adalah menggunakan persamaan momentum dan energi, seperti berikut :

$$
\begin{aligned}
& \frac{\partial \rho u_{j}}{\partial t}+\nabla \rho \eta u_{i} u_{j}=-\nabla P+\nabla 2 \mu u_{i}+\rho g_{i}-\nabla u_{i} d \\
& \frac{\partial \rho u_{j}}{\partial t}+\nabla \rho u_{i}=\nabla k u_{i}
\end{aligned}
$$

dengan $\rho=$ massa jenis $\left(1.2 \mathrm{~kg} / \mathrm{m}^{2}\right), u=$ kecepatan arah sumbu $x(3 \mathrm{~m} / \mathrm{s}), v=$ kecepatan arah sumbu $y(2 \mathrm{~m} / \mathrm{s}), P=$ tekanan $(10 \mathrm{~Pa}), g=$ percepatan gravitasi $\left(10 \mathrm{~m} / \mathrm{s}^{2}\right), \mu=$ kekentalan zat $(1.6 \times 10-5 \mathrm{~kg} / \mathrm{m} \mathrm{s}), \eta=$ panas efisien $(77.0 \%)$, dan $k=$ konduktivitas $\left(0.026 \mathrm{~W} / \mathrm{m}-{ }^{\circ} \mathrm{C}\right)$ [8].

Selanjutnya kita diskritisasi persamaan tersebut menggunakan teknik diskritisasi QUICK [3]. Bentuk umum skema QUICK untuk kecepatan lebih besar dari nol adalah:

$$
\phi_{n}=\phi(i, j)+g_{1}[\phi(i+1, j)-\phi(i, j)]+g_{2}[\phi(i, j)-\phi(i-1, j)]
$$


dengan bobot $g_{1}$ :

$$
g_{1}=\frac{\left[\phi_{n}(i, j)-\phi(i, j)\right]\left[\phi_{n}(i, j)-\phi(i-1, j)\right]}{[\phi(i+1, j)-\phi(i, j)][\phi(i+1, j)-\phi(i-1, j)]}
$$

dengan bobot untuk $g_{2}$

$$
g_{2}=\frac{\left[\phi_{n}(i, j)-\phi(i, j)\right]\left[\phi_{n}(i, j)-\phi(i-1, j)\right]}{[\phi(i+1, j)-\phi(i, j)][\phi(i+1, j)-\phi(i-1, j)]}
$$

Berdasarkan diskritisasi QUICK, maka diperoleh nilai untuk $g_{1}$ dan $g_{2}$ yaitu:

$$
\begin{aligned}
& g_{1}=\frac{\left(\frac{1}{2} h\right)\left(\frac{3}{2} h\right)}{(h)(2 h)}=\frac{3}{8} \\
& g_{2}=\frac{\left(\frac{1}{2} h\right)\left(\frac{1}{2} h\right)}{(h)(2 h)}=\frac{1}{8}
\end{aligned}
$$

Substitusikan nilai $g_{1}$ dan $g_{2}$ ke Persamaan (3), sehingga diperoleh rumus untuk $\phi_{e}(i, j)$ :

$$
\begin{aligned}
\phi_{e}(i, j) & =\phi(i, j)+g_{1}[\phi(i+1, j)-\phi(i, j)]+g_{2}[\phi(i, j)-\phi(i-1, j)] \\
& =\phi(i, j)+\frac{3}{8}[\phi(i+1, j)-\phi(i, j)]+\frac{1}{8}[\phi(i, j)-\phi(i-1, j)] \\
& =-\frac{1}{8} \phi(i-1, j)+\frac{3}{4} \phi(i, j)+\frac{3}{8} \phi(i+1, j)
\end{aligned}
$$

Dengan cara yang sama diperoleh nilai $\phi_{w}(i, j), \phi_{n}(i, j)$ dan $\phi_{s}(i, j)$, yaitu :

$$
\begin{aligned}
& \phi_{w}(i, j)=-\frac{1}{8} \phi(i-2, j)+\frac{3}{4} \phi(i-1, j)+\frac{3}{8} \phi(i, j) \\
& \phi_{n}(i, j)=-\frac{1}{8} \phi(i, j-1)+\frac{3}{4} \phi(i, j)+\frac{3}{8} \phi(i, j+1) \\
& \phi_{s}(i, j)=-\frac{1}{8} \phi(i, j-2)+\frac{3}{4} \phi(i, j-1)+\frac{3}{8} \phi(i, j)
\end{aligned}
$$

\section{METODE PENELITIAN}

Secara umum prosedur yang dilakukan yaitu melakukan studi pustaka tentang perpindahan panas pada penerima volumetrik (pada proses ini dilakukan pengumpulan data dan teori-teori yang mendukung). Selanjutnya akan dibuat model matematika dari persamaan momentum dan persamaan energi sesuai dengan data yang diperoleh, sehingga akan dibentuk suatu model baru perpindahan panas dalam penerima volumetrik yang dipengaruhi kecepatan angin dan temperatur sekitar menara surya. Langkah selanjutnya selesaikan model matematika yang sudah didapat menggunakan metode volume hingga (pada tahap ini dibentuk suatu penyelesaian dengan metode volume hingga dari permasalahan perpindahan panas pada penerima volumetrik). Setelah itu, dibuat algoritma dari pemodelan matematika dengan menggunakan software MATLAB (pada tahap ini dilakukan pembuatan program komputer dari pemodelan perpindahan panas dalam penerima volumetrik yang dipengaruhi kecepatan angin serta temperatur sekitar menara surya dengan bantuan aplikasi MATLAB). Kemudian dijalankan program yang terbentuk untuk dianalisis hasil perpindahan panas pada penerima volumetrik. Simulasi menggunakan FLUENT untuk proses perpindahan panas dalam penerima volumetrik (pada tahap ini akan dilakukan simulasi dari perpindahan panas pada penerima volumetrik dipengaruhi kecepatan angin dan temperatur sekitar menara surya dengan bantuan aplikasi FLUENT). Menganalisis hasil simulasi dengan FLUENT. Tahap terakhir yaitu memberikan kesimpulan dari data yang dihasilkan. 


\section{HASIL DAN PEMBAHASAN}

\subsection{Simulasi MATLAB}

Analisis numerik pada proses perpindahan panas dalam penerima volumetrik dibangun oleh persamaan momentum dan persamaan energi, yang dilakukan penurunan rumus dengan menggunakan metode volume hingga serta diskritisasi menggunakan Teknik Diskritisasi Quadratic Upwind Interpolation Convertive Kinetis (QUICK)[3].

Pada penelitian ini simulasi dilakukan menggunakan aplikasi MATLAB dan FLUENT [4]. Aplikasi MATLAB digunakan dalam mendeskripsikan peningkatan suhu pada penerima volumetrik. Terdapat dua grafik hasil simulasi aliran udara yaitu simulasi yang dilakukan untuk mengetahui proses perpindahan panas dalam penerima volumetrik berdasarkan kecepatan angin dan simulasi kedua yang dilakukan untuk mengetahui proses perpindahan panas dalam penerima volumetrik berdasarkan tenperatur sekitar menara surya. Grafik pengaruh kecepatan angin dapat dilihat pada Gambar 3 dan grafik pengaruh temperatur sekitar dapat dilihat pada Gambar 4.

Dari hasil simulasi perpindahan panas dalam penerima volumetrik berdasarkan kecepatan angin dan temperatur sekitar menara surya terhadap temperatur suhu pada penerima volumetrik. Pada kecepatan angin berturut-turut sebesar $2 \mathrm{~m} / \mathrm{s}, 2.5 \mathrm{~m} / \mathrm{s}$ dan $3 \mathrm{~m} / \mathrm{s}$ diperoleh suhu tertinggi yaitu $659.38^{\circ} \mathrm{C}, 529.72^{\circ} \mathrm{C}$ dan $166.1^{\circ} \mathrm{C}$. Simulasi kedua berdasarkan temperatur sekitar menara surya pada proses perpindahan panas dalam penerima volumetrik dengan kecepatan angin $2 \mathrm{~m} / \mathrm{s}$. Temperatur yang digunakan berturut-turut sebesar $27^{\circ} \mathrm{C}, 32^{\circ} \mathrm{C}$ dan $37^{\circ} \mathrm{C}$ dapat dilihat pada Gambar 4 bahwa suhu pada penerima volumetrik mengalami kenaikan sebesar $25.722^{\circ} \mathrm{C}, 242.27^{\circ} \mathrm{C}$ dan $768.55^{\circ} \mathrm{C}$.

Berdasarkan hasil simulasi dapat dilihat bahwa terjadi peningkatan temperatur pada penerima volumetrik. Jika kecepatan angin semakin besar maka proses perpindahan panas yang terjadi dalam penerima volumetrik mengalami penurunan begitu pula sebaliknya. Sedangkan jika temperatur sekitar menara surya semakin besar maka proses perpindahan panas yang terjadi dalam penerima volumetrik mengalami peningkatan.

Penggunaan metode volume hingga dalam menyelesaikan model matematika aliran udara pada penerima volumetrik efektif karena nilai error relatif yang diperoleh kurang dari nilai toleransi yang ditentukan, error relatif yang diperoleh sebesar 0.009675 dan 0.001366 .

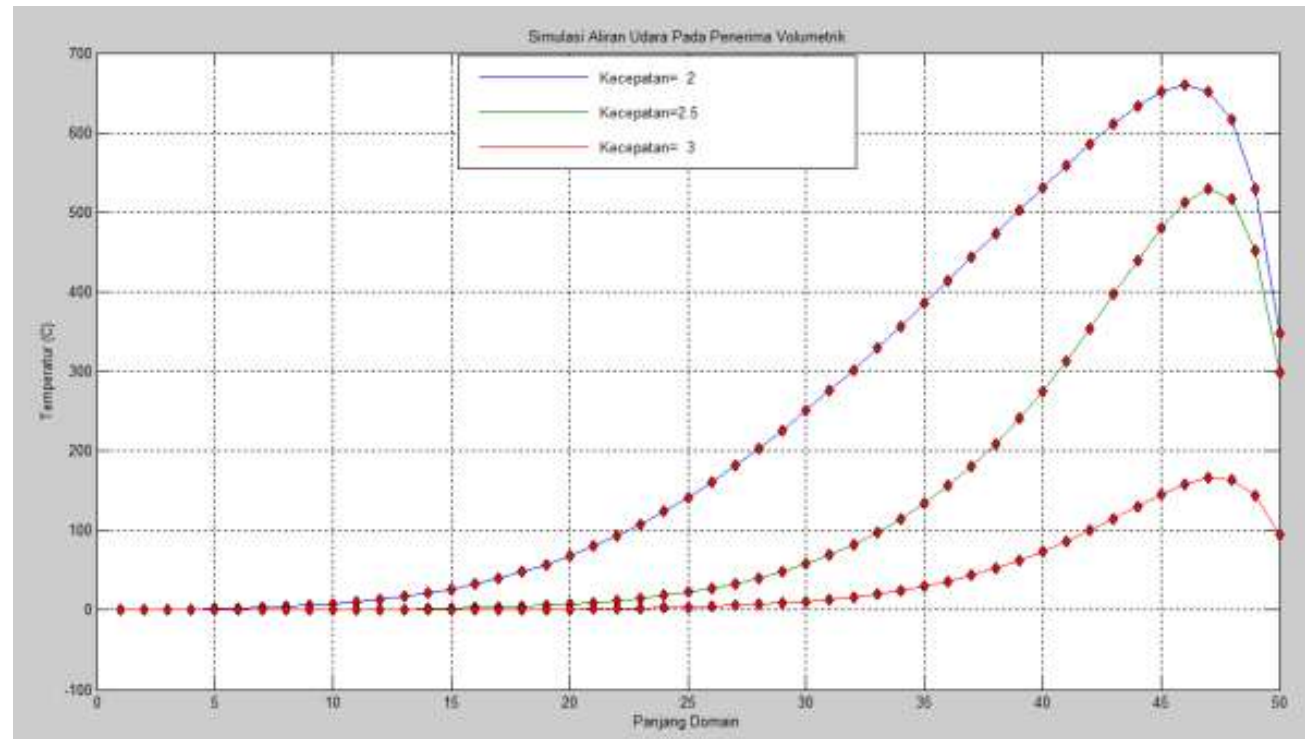

Gambar 3. Plot simulasi berdasarkan kecepatan angin $(2,2.5$ dan $3 \mathrm{~m} / \mathrm{s})$ 


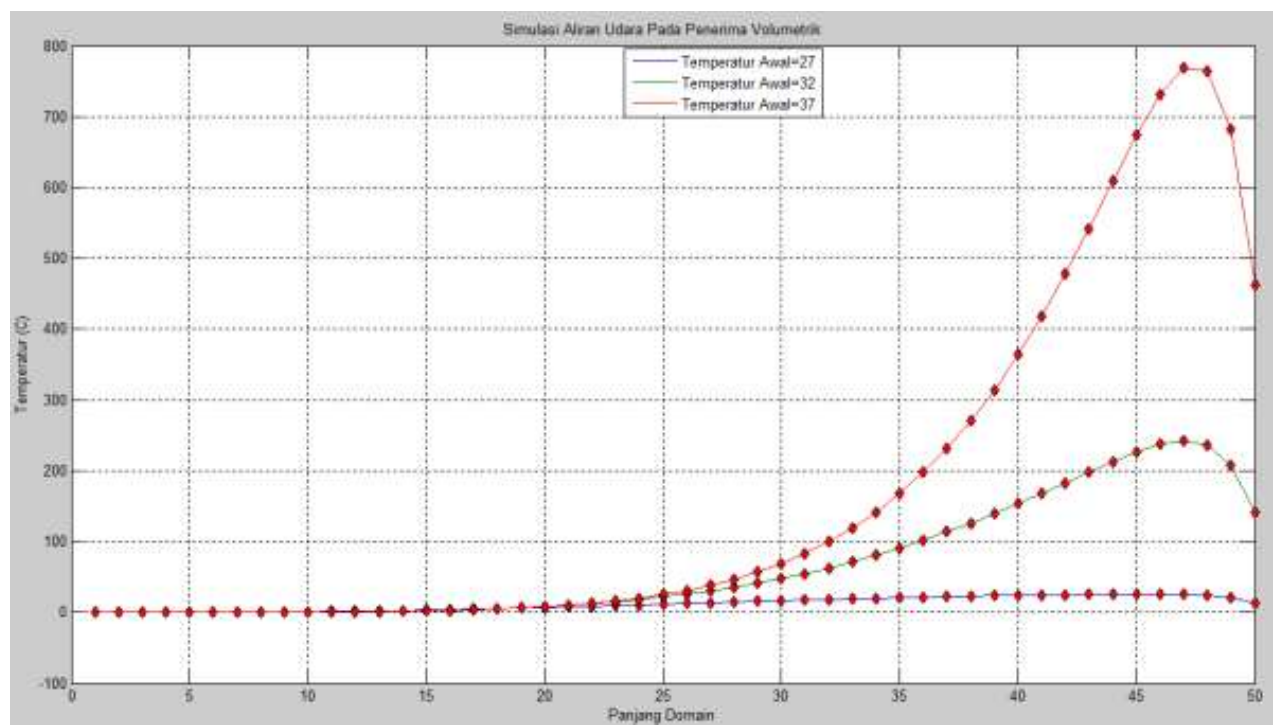

Gambar 4. Plot simulasi berdasarkan temperatur $\left(27,32\right.$ dan $\left.37^{\circ} \mathrm{C}\right)$

\subsection{Simulasi FLUENT}

Pada simulasi ini digunakan software FLUENT yaitu dengan menggambarkan objek yang akan diteliti dalam software Gambit terlebih dahulu untuk kemudian dilakukan simulasi dengan software FLUENT tersebut [5]. Simulasi ini dibedakan untuk menentukan perbedaan proses perpindahan panas dalam penerima volumetrik berdasarkan kecepatan angin dan temperatur disekitar menara surya.

Pada simulasi pertama digambarkan penerima volumetrik. Pada Gambar 5(a) digunakan temperatur disekitar menara surya adalah $27^{\circ} \mathrm{C}$ setara dengan $300 \mathrm{~K}$, sedangkan Gambar 5(b) menggunakan temperatur sebesar $32^{\circ} \mathrm{C}$ setara dengan $305 \mathrm{~K}$, dan Gambar 5(c) menggunakan temperatur sekitar sebesar $37^{\circ} \mathrm{C}$ setara dengan $310 \mathrm{~K}$.
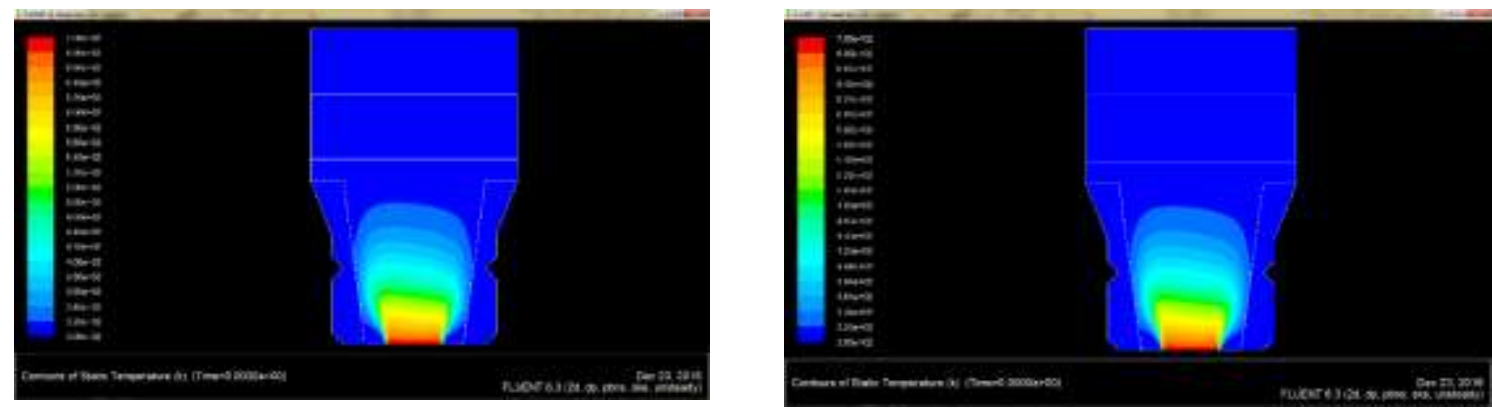

(a)

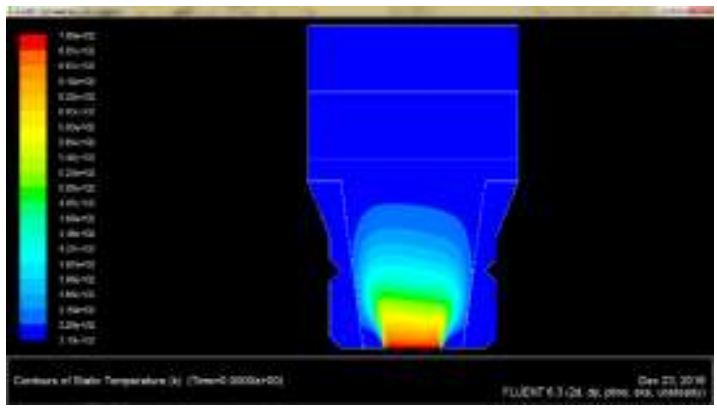

(b)

(c)

Gambar 5. Simulasi FLUENT Berdasarkan Temperatur Sekitar sebesar $27^{\circ} \mathrm{C}$ (a), $32^{\circ} \mathrm{C}$ (b) dan $37^{\circ} \mathrm{C}$ (c)

Dari hasil simulasi diketahui bahwa temperatur disekitar menara surya mempengaruhi besarnya temperatur pada penerima volumetrik. Hal ini dapat dilihat di tabel warna sebelah kiri menunjukkan besarnya temperatur yang berbeda-beda setiap warnanya. Perubahan terjadi ketika temperatur sekitar menara diperbesar maka besarnya temperatur pada penerima volumetrik akan mengalami kenaikan. Maka simulasi tersebut sesuai 
bahwa semakin besar temperatur sekitar menara surya maka semakin besar pula temperatur pada penerima volumetrik [6].
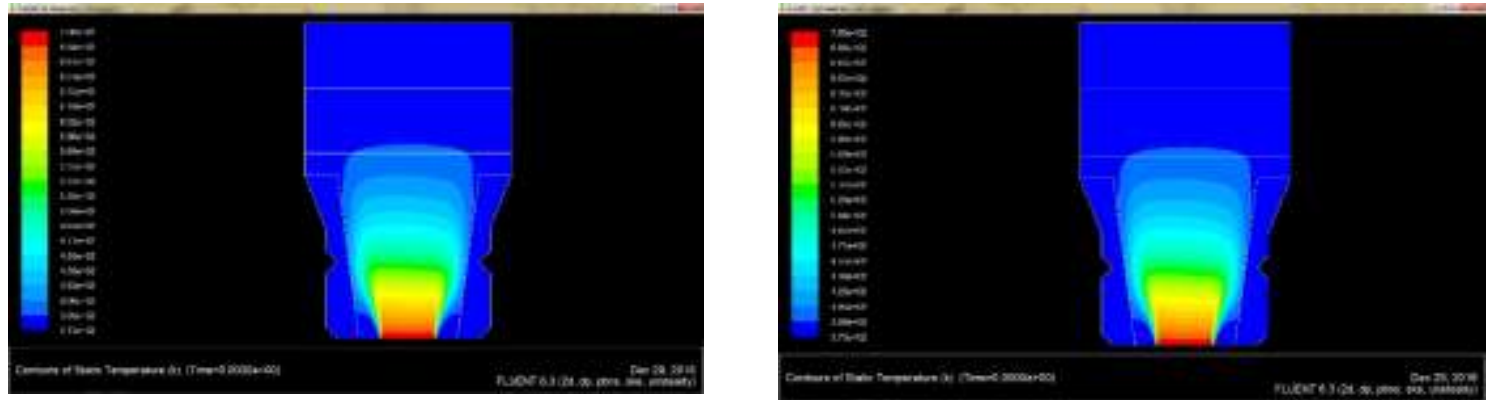

(a)

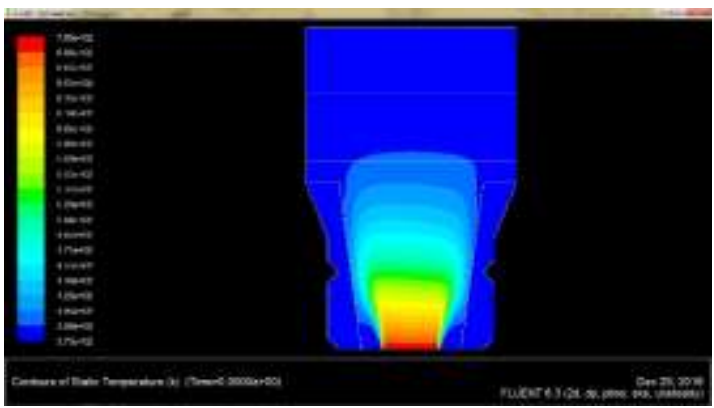

(b)

(c)

Gambar 6. Simulasi FLUENT Berdasarkan Kecepatan Angin sebesar $2 \mathrm{~m} / \mathrm{s}(\mathrm{a}), 2.5 \mathrm{~m} / \mathrm{s}$ (b) dan $3 \mathrm{~m} / \mathrm{s}$ (c)

Pada simulasi kedua ini akan diteliti tentang proses perpindahan panas dalam penerima volumetrik berdasarkan besarnya kecepatan angin. Pada Gambar 6(a) merupakan simulasi menggunakan kecepatan angin sebesar $2 \mathrm{~m} / \mathrm{s}$, Gambar 6(b) merupakan simulasi menggunakan kecepatan angin sebesar $2.5 \mathrm{~m} / \mathrm{s}$ serta Gambar 6(c) merupakan simulasi menggunakan kecepatan angin sebesar $3 \mathrm{~m} / \mathrm{s}$.

Berdasarkan hasil simulasi tersebut menunjukkan terjadinya penurunan suhu di dalam penerima volumetrik ketika kecepatan angin diperbesar. Pada Gambar 6(a), 6(b) serta 6(c) sekilas memiliki hasil simulasi yang sama. Hal ini dikarenakan perubahan kecepatan angin yang tidak terlalu signifikan. Maka simulasi tersebut sesuai bahwa semakin besar kecepatan angin maka temperatur pada daerah penerima volumetrik mengalami penurunan [7].

\section{KESIMPULAN}

Berdasarkan hasil penelitian yang sudah dilakukan dan dilanjutkan dengan simulasi dengan berbantuan software MATLAB dan FLUENT maka kesimpulan yang didapatkan yaitu adanya pengaruh kecepatan angin dan temperatur sekitar menara surya dimana ketika kecepatan angin berubah sebesar $0.5 \mathrm{~m} / \mathrm{s}$ maka rata-rata suhu di dalam penerima volumetrik mengalami penurunan sebesar $200^{\circ} \mathrm{C}$ begitu pula ketika temperatur sekitar menara berubah sebesar $5^{\circ} \mathrm{C}$ maka rata-rata suhu di dalam penerima volumetrik mengalami kenaikan sebesar $300^{\circ} \mathrm{C}$. Dimana semakin besar kecepatan angin maka proses perpindahan panas semakin menurun begitu pula sebaliknya dan semakin besar temperatur sekitar menara surya maka proses perpindahan panas semakin meningkat begitu pula sebaliknya. Saran yang dapat diberikan oleh peneliti setelah mengadakan penelitian ini yaitu pemodelan matematika aliran udara pada penerima volumetrik dapat dikembangkan dengan melakukan penelitian menggunakan pengaruh lainnya.

\section{UCAPAN TERIMA KASIH}

Ucapan terimakasih kami sampaikan kepada pihak Universitas Jember yang telah memberikan bantuan dana, fasilitas sehingga terselesaikannya penelitian ini. 


\section{DAFTAR PUSTAKA}

[1] Aspley, D. D. Quantitative Properties of F.D. Schemes, Lecture handout:CFD. Manchester: University of Manchester. 2007.

[2] Lovegrove, K. and Stein, W. Concetrating Solar Power Technology: Principles, Development and Applications. Oxford: Woodhead Publishing. 2012.

[3] Fatahillah, A. Analisis Numerik Profil Sedimentasi Pasir Pada Pertemuan Dua Sungai Berbantuan Software Fluent. Kadikma. 2014; 5(3) : 35-40.

[4] Qoriatul, dkk. Analisis Model Mathematical in Heat Exchanger Shell and Tube Type Used in PT. Pupuk Kaltim Tbk. Kadikma. 2013; 4(1) : 7-14

[5] Widodo, B. dkk. Mathematical Modeling and Numerical Solution of Iron Corrosion Problem Based on Condensation Chemical Properties. IIUM Engineering Journal. 2014; 12(6) : 117-127

[6] L., Antonio. Volumetric receivers in Solar Thermal Power Plants with Central Receiver System technology: A review. 2011.

[7] Munson, Bruce R., dkk. Mekanika Fluida Edisi 4. Jakarta: Erlangga. 2004.

[8] Roldan, M.I., dkk. Computational fluid dynamics evaluation of the operating conditions for volumetric receiver installed in a solar tower. Energy Journal. 2016; $94: 844-856$

[9] Hoffmann, J.F., dkk. A thermocline thermal energy storage system with filler materials for concetrated solar power plants: Experimental data and numerical model sensitivity to different experimental tank scales. Applied Thermal Enineering. 2016; $100:$ 753-761

[10] Pitz-Paal, Robert., dkk. Consentrating Solar Power in Europe, the Middle East and North Africa: Achieving Its Potential.2013 
